\title{
Climate Governance is Failing Us: We All Need to Respond
}

\author{
Chris Riedy and Ian M. McGregor, University of Technology, Sydney, Guest \\ editors
}

The primary international treaty that guides global climate governance is the United Nations Framework Convention on Climate Change (UNFCCC), agreed at the Rio Earth Summit in 1992. The UNFCCC entered into force in 1994 and has been ratified by 195 countries, known as Parties to the UNFCCC. Since it came into force, there have been annual Conferences of the Parties (COPs) each year, starting in 1995. The UNFCCC contains no binding emission reduction targets, so negotiations were launched in 1995 to strengthen commitments under the UNFCC. In 1997, at the Third Conference of the Parties (COP-3), the Parties adopted the Kyoto Protocol (KP), which set binding emission reduction targets for industrialised countries. These targets applied to average annual emissions during what is known as the First Commitment Period, between 2008 and 2012. As the First Commitment Period under the KP ends in 2012, the Parties commenced negotiations on the details of a Second Commitment Period in 2005, at COP-11 in Montreal. Then, in 2007, the Parties agreed to the Bali Action Plan at COP-13. Under the Bali Action Plan, Parties agreed that negotiations would commence on a parallel agreement on Long-term Cooperative Action (LCA) under the UNFCCC. The aim of the Bali Action Plan was that negotiations under both the KP and LCA tracks would be completed so that an agreement could be signed at COP-15 in Copenhagen in late 2009 (UNFCCC 2011a). As a consequence of this history, and the growth of a vocal climate action movement around the world, COP-15 received unprecedented media, political and public attention. For the global climate action

PORTAL Journal of Multidisciplinary International Studies, vol. 8, no. 3, September 2011. Special issue details: Global Climate Change Policy: Post-Copenhagen Discord Special Issue, guest edited by Chris Riedy and Ian McGregor. 
movement, Copenhagen was supposed to deliver a fair, ambitious and binding international treaty to reduce greenhouse gas emissions (CAN International 2009).

However, in the wake of the global financial crisis and Great Recession of 2008-2009, the political will for negotiating such a treaty was far from universal. Despite attracting some 120 Heads of State, which Dimitrov (2010: 18) claims was 'the highest concentration of robust decision-making power the world had seen,' the outcome of Copenhagen was the Copenhagen Accord, which is not binding, and many have claimed is neither fair nor ambitious. Negotiated in the last hours of the conference by a small group of countries, including the USA, China, Brazil, India and South Africa, the Accord was noted, but not adopted, by COP-15.

In the wake of COP-15, assessments of what had been achieved were mixed. While the conference had failed to deliver a binding international treaty, it did deliver an agreement that provided an opportunity for all countries to pledge emission reductions. Nevertheless, most in the global climate action movement were disappointed with the outcome. Oxfam captured the typical sentiment when it called the Accord 'little more than agreement to keep talking' (Oxfam 2009: 1).

A year later, at COP-16 in Cancun, the Parties adopted the Cancun Agreements. These Agreements effectively formalised the Copenhagen Accord, establishing an objective of reducing human-generated greenhouse gas emissions over time to keep the global average temperature rise below two degrees above pre-industrial levels and to consider strengthening the goal to 1.5 degrees (UNFCCC 2011b). The Copenhagen Accord also provided a mechanism for all countries to pledge emission reductions. At least 89 countries have now pledged to limit their emissions, accounting for more than $80 \%$ of global emissions (DCCEE 2011).

However, as COP-17 approaches in Durban in December 2011, ${ }^{1}$ global climate change governance remains plagued by seemingly intractable disputes. First, many argue that current climate science supports even stronger limits on temperature rise than the twodegree limit on temperature rise contemplated in the Cancun Agreements. For example, the Alliance of Small Island States advocates limiting temperature rise to no more than 1.5 degrees (AOSIS 2009) and some climate scientists have called for a return of carbon

\footnotetext{
${ }^{1}$ This special issue went to press during the Durban meeting.
} 
dioxide levels in the atmosphere to 350ppm (Hansen et al. 2008). Second, the emission reductions pledged by countries to date are not sufficient to meet even the objective listed in the Cancun Agreements of limiting temperature rise to no more than two degrees. Climate Action Tracker (Hohne et al. 2011) estimates they will lead to temperature rise of between 2.6 and 4 degrees. Third, the Copenhagen Accord and the Cancun Agreements are non-binding. If countries fail to achieve the emission reductions they have pledged, then temperature rises will be even higher than the range listed above. The past record of nations in meeting their emission reduction commitments does not inspire confidence in the emission reductions being achieved. Fourth, serious barriers exist to the establishment of a binding treaty, including ongoing disputes over the legal form of a treaty, its relationship to the Kyoto Protocol, financing mechanisms, and the fair share of emission reductions that different nations should take on. Most developing countries support a Second Commitment Period of the Kyoto Protocol alongside an agreement on Long-term Cooperative Action, while many developed countries are resisting an updated Kyoto Protocol. Fifth, the requirement for international consensus on decisions under the UNFCCC makes progress painfully slow and subject to veto by nations pursuing what they see as their national interest. Some have questioned whether an effective international response to climate change is even possible under such a system (Naim 2009).

We should not be surprised that agreement on an effective global climate governance system is proving so difficult. As Mike Hulme (2009) points out, there are many reasons to disagree on climate change. It is a problem with some unprecedented characteristics that challenge governance systems like never before. It is a global commons problem, requiring simultaneous action by diverse governments, businesses and people on a scale that has never been achieved. It is a creeping problem; people perceive climate change as affecting other people in other places and times, rather than here and now, making it easy to postpone action or dismiss the problem entirely. It is the product of complex systems whose future behaviour cannot be predicted with complete certainty, making climate science an ideological battleground. It challenges the hegemonic economic system and its unsustainable reliance on infinite sources of material and infinite sinks. It requires complete transformation of the fossil fuel based energy system that has delivered a powerful section of humanity unprecedented material wealth. 
New approaches to global governance, then, are needed to respond to the unprecedented challenge of climate change. It is with this need for fresh thinking in mind that we decided to put together this special issue on global climate change governance in the wake of Copenhagen.

In this special issue, we have gathered six diverse articles that each look at the climate governance problem through a very different lens. One thing all the authors agree on is that the current system of climate governance is not delivering an effective response to climate change - the climate governance system is failing humanity and is in need of repair. However, the authors have very different prescriptions for reform of climate governance, ranging from minor reforms to radical overturning of the existing regime.

Brian Fisher's article assumes that the UNFCCC will remain a key site for global climate governance but argues for an important shift in the focus of the negotiations. He contends that the negotiations are hampered by the lack of a shared long-term vision and by the narrow focus on emission reduction targets and timetables. Seeking an alternative approach, Fisher looks closely at the wording of Article 2 of the UNFCCC, which sets an objective of avoiding dangerous interference with the climate system. Through this examination, he identifies five alternative approaches that could theoretically be employed to achieve the objectives of Article 2. Each approach focuses on a different element of what he calls the 'climate process': local anthropogenic drivers of emission (i.e. sources); global anthropogenic structural drivers; national greenhouse gas emissions (i.e. the current targets and timetables approach); the fairness of the process of international climate negotiations; and the outcomes of climate change.

After considering the advantages and disadvantages of each of these five approaches, Fisher argues that the international negotiations should concentrate on agreed actions to eliminate emission sources and minimise negative outcomes of climate change. In practice, this would mean the abandonment of national emission reduction targets in favour of collaborative international development of clean energy technologies, alongside adaptation strategies to protect the most vulnerable. This kind of reform of the UNFCCC process offers one possible path beyond the current impasse of global climate governance. However, despite numerous proposals for institutional reform of climate governance in recent years, the pace of change is glacial. It remains to be seen whether the type of proposals that Fisher puts forward can gain some traction. Further, Fisher's 
proposals leave the UNFCCC intact as the key site of global climate governance, a position that sits awkwardly with some of the other articles in this special issue.

One proposed alternative model of global climate governance is minilateralism, which Jeffrey McGee investigates in his contribution to the special issue. It is often observed that the UNFCCC consensus rules make any meaningful agreement between the 195 Parties to the UNFCCC difficult. While discussions about reform of these rules continue, and the overruling of Bolivia's express objection to the Cancun Agreements sets an interesting precedent for moving beyond simple consensus (Rajamani 2011), some argue that the multilateral UNFCCC should be abandoned altogether in favour of negotiations within smaller groups of nations. Proponents of minilateralism argue that convening a smaller group of key states, perhaps the 20 biggest emitters or the G20 (which is essentially the same group), is a more promising route to overcoming barriers to an international agreement on climate change response. This is a utilitarian position, based on the observation that an agreement to reduce emissions between the 20 nations responsible for 80 percent of emissions would essentially solve the problem.

McGee positions minilateralism as an emergent discourse in the field of climate governance. He assesses the key objections to minilateralism, most worrying of which is the exclusion of those most impacted by climate change from the negotiations under many minilateral models. He demonstrates that minilateralism is inconsistent with both cosmopolitan and deliberative theories of democracy and therefore does not advocate a solely minilateral approach to climate governance. However, McGee draws on John Dryzek's work to argue that emergent discourses that gather power either replace existing discourses or are accommodated into them. He sees potential for some of the positive elements of a minilateral discourse to be incorporated into the UNFCCC, without compromising democracy. For example, the UNFCCC could form 'a peak body of the twenty most responsible, vulnerable and capable states plus representatives of key NGO groups' that would become an influential advisor to the process without having ultimate decision making power.

Whether international climate negotiations are multilateral or minilateral, some key challenges remain unchanged. One of these is the continuing failure of the United States to commit to strong domestic action on climate change and the critical role this plays in undermining trust in the international negotiations. As the largest historical emitter of 
greenhouse gases, the second largest current emitter and one of the highest per capita emitters in the world, other nations look to the USA to show leadership in reducing greenhouse gas emissions. To date, that leadership has been sadly lacking.

Bob Brinkmann and Sandra Garren provide a comprehensive examination of the recent development of climate change policy in the United States through the Congress, the Environmental Protection Agency (EPA) and the courts. As the only major developed nation not to ratify the Kyoto Protocol, the United States has long been a drag on international climate change response. Brinkmann and Garren argue that, while there were some hopeful developments under President Obama, the election of the Republican-dominated 112th Congress, with many members of Congress openly questioning the science of anthropogenic climate change, has dashed any hope for domestic legislation to respond to climate change. Brinkmann and Garren look at alternative responses, particularly the regulation of greenhouse gases by the EPA and the use of the court system to litigate for stronger greenhouse gas controls. It is the former that remains the greatest source of hope for greenhouse gas emission reduction in the United States. But it is only a small glimmer of hope in a political landscape that seems gridlocked on climate change and many other issues. The prospects of the United States playing a leadership role in the international response to climate change seem remote at this time.

The remaining papers look at alternatives to the current system of State-based international negotiations through the UNFCCC. Chris Riedy and Jade Herriman investigate the potential to develop a system of global climate governance that is more consistent with principles of deliberative democracy. Deliberative democracy puts talking, rather than voting, at the heart of democracy. In the current system of global climate governance, where nation states negotiate on behalf of their constituencies with little direct citizen involvement, opportunities for citizens to deliberate on global responses to climate change and influence the negotiations are rare. In the months before COP-15, an ambitious project called World Wide Views on Global Warming (WWViews) sought to give citizens a voice in the international negotiations. On 26 September 2009, WWViews brought together 4,000 citizens in 38 countries to deliberate on international climate policy and make recommendations to the negotiators meeting in Copenhagen. As two of the organisers of the Australian WWViews event, 
Riedy and Herriman provide a reflective evaluation of WWViews. They examine the role that deliberative mini-publics, like WWViews, can play in facilitating the emergence of a global deliberative system for climate change response. Their evaluation is mixed; while the project was well managed, enjoyed by participants and demonstrated the feasibility of convening global mini-publics, it arguably achieved little influence on global climate change policy. This is a recurring problem for deliberative mini-publics at all scales. Riedy and Herriman argue that global mini-publics do have a role in democratizing the global climate governance system. But they need to: place greater priority on the quality of deliberation; provide flexibility to respond to diverse cultural and political contexts; maximize their potential for influence by running over longer time periods; and bring global citizens together in international processes rather than discrete national events.

While organized deliberative democracy events may have a role in democratizing global climate governance, James Goodman argues for more radical forms of democracy. For Goodman, climate governance is a space that needs to be confronted, contested and disordered by global civil society. He argues that the official climate governance discourse reproduces hegemonic power relations and supports exploitation of the South by the North. He traces the emergence of unofficial discourses of climate justice that seek to disorder and contest the official discourse of climate governance. This nonofficial climate justice discourse focuses attention on the devastating impacts of climate change on those in the South and on specific sites of climate policy failure. Sites of proposed power station and runway expansions, for example, highlight the contradiction between official climate policy and climate practice and have attracted particular forms of protest, such as climate camps.

For Goodman, the prevailing climate responses, such as carbon trading and offsets, are maladaptive in that they serve to defend a regime that ultimately needs to undergo transformative change. These responses are part of the system that created the problem and will therefore fail. Central to Goodman's argument is the idea of climate justice and the contention that the current climate governance regime is unjust and needs to be disrupted. The recent emergence of the Occupy movement, drawing attention to economic injustice and calling for economic transformation, seems to add further weight to Goodman's argument. 
Where most of the other contributors seek new orderings of the climate governance system, Jonathan Marshall calls for greater disorder, or at least greater attention to the disorder that already exists. Marshall frames climate change and the failure of Copenhagen as a psychosocial disorder, arguing that the disorder associated with climate change causes our certainties, alliances and social categories to break down. He compares the disorder, chaos and uncertainty of Copenhagen with the disorder, chaos and uncertainty of editing a collection of essays on depth psychology and climate change. He uses the metaphor of 'thrum'-'the fringe of warp threads left on a loom after the cloth has been cut off; ... the odd bits of waste'- to make the point that disorder is not something to be defined away by order but an essential and normal part of existence. He looks at the temporary, fragile and disordered networks that form around climate change and asks that our social theories include this reality, rather than seeking to impose an impossible order.

From this position, Marshall goes on to contest the idea that justice is a useful framework for approaching climate governance, as it requires the establishment of a particular order that relies on an 'us and them' mentality and will itself become disordered. This places him in direct opposition with Goodman's call for a justice-based approach. Indeed, Marshall would probably question all of the attempts to establish new climate governance orders put forward by the other authors. Instead, Marshall asks us to listen to the disorder within climate change rather than discarding it, in the hope that this will help to render it symbolically conceivable. Ultimately, Marshall asks us to embrace disordered, fragmentary and fragile networks as our response to climate change: 'Rather than demanding fairness and justice, perhaps we can ask all who are concerned to act now, to cut back emissions, to find new lives and morals which apply to them rather than are demanded of others.'

We are left, then, with six very different perspectives on global climate governance that sit together somewhat uncomfortably. Like the climate negotiations themselves, the differences seem irreconcilable. For us, the way forward is in Marshall's call for all to act now in ways that they can. The Nobel Prize winning economist Elinor Ostrom has argued that we need a polycentric approach to climate change, characterised by action across all scales and sectors (Ostrom 2010). When dealing with an unprecedented global commons problem like climate change, we cannot hope to guess which kind of 
responses will end up being most effective. What is needed, in this era of uncertainty and urgency, is conscious experimentation with many different modes of governance, from global to local, to see which will bear fruit.

The authors in this special issue present six ideas for new experiments in global governance that deserve to be tested in practice. While the focus in this special issue is on global governance, the most effective responses to climate change may emerge at local, regional or national scales. Nevertheless, we should continue to pursue effective global climate governance, just as we should pursue effective responses at all these other scales. We all need to act, within our spheres of influence, if we are to successfully tackle global climate change.

\section{Reference List}

AOSIS 2009, Alliance of Small Island States (AOSIS) Declaration on Climate Change 2009. Online, available: http://www.aosis.info/documents/AOSISSummitDeclarationSept21FINAL.pdf [Accessed 1 Sep. 2011].

Climate Action Network (CAN) International 2009, Fair, Ambitious and Binding: Essentials for a Successful Climate Deal. Online, available: http://www.climatenetwork.org/publication/cans-fairambitious-binding-essentials-successful-climate-deal [Accessed 1 Sep. 2011].

DCCEE 2011, 'International Pledges,' Department of Climate Change and Energy Efficiency. Online, available: http://www.climatechange.gov.au/en/government/international/global-action-facts-andfiction/international-pledges.aspx [Accessed 1 Sep. 2011].

Dimitrov, R. S. 2010, 'Inside Copenhagen: The State of Climate Governance,' Global Environmental Politics, vol. 10, no. 2, 18-24.

Hansen, J., et al. 2008, 'Target Atmospheric CO2: Where Should Humanity Aim?,' The Open Atmospheric Science Journal, vol. 2, 217-231.

Hohne, N., Hare, B., Schaeffer, M., Chen, C., Vieweg, M. \& Moltmann, S. 2011, 'Emissions and CO2 Concentrations at Record Highs: Developed Countries' Ambition Stalled while Developing Countries Gearing Up to Act Most,' Climate Action Tracker. Online, available: http://www.climateactiontracker.org/CAT_update_Bonn_2011-06-16.pdf [Accessed 1 Sep. 2011].

Hulme, M. 2009, Why We Disagree About Climate Change: Understanding Controversy, Inaction and Opportunity. Cambridge University Press, Cambridge.

Naim, M. 2009, 'Minilateralism: The Magic Number to Get Real International Aaction,' Foreign Policy, no. $173,135-136$.

Ostrom, E. 2010, 'Nested Externalities and Polycentric Institutions: Must We Wait for Global Solutions to Climate Change Before Taking Actions at Other Scales?,' Economic Theory, OnlineFirst, August 6. DOI: 10.1007/s00199-010-0558-6.

Oxfam. 2009, Climate Shame: Get Back to the Table - Initial Analysis of the Copenhagen Climate Talks, Oxfam International. Online, available: http://www.oxfam.org/sites/www.oxfam.org/files/briefingnote-climate-shame-get-back-to-the-table.pdf [Accessed 1 Sep. 2011].

Rajamani, L. 2011, 'The Cancun Climate Agreements: Reading the Text, Subtext and Tea Leaves,' International and Comparative Law Quarterly, vol. 60, no. 2, 499-519.

UNFCCC 2011a, 'Bali Road Map,' United Nations Framework Convention on Climate Change. Online, available: http://unfccc.int/key_documents/bali_road_map/items/6447.php [Accessed 1 Sep. 2011]. 2011b, Report of the Conference of the Parties on its Sixteenth Session, Held in Cancun from 29 November to 10 December 2010. Addendum. Part Two: Action Taken by the Conference of the Parties at its Sixteenth Session, United Nations Framework Convention on Climate Change. Online, available: http://unfccc.int/resource/docs/2010/cop16/eng/07a02.pdf [Accessed 1 Sep. 2011]. 